\title{
Simultaneous Moyamoya disease and cervical spinal cord low-grade astrocytoma in a child with neurofibromatosis type 1
}

\author{
Jeffrey J Gold, ${ }^{1}$ Chris E Dory, ${ }^{2}$ Michael L Levy, ${ }^{3}$ John Ross Crawford ${ }^{4}$
}

1 Department of Neurosciences, University of California San Diego, San Diego, California, USA

${ }^{2}$ Department of Radiology, University of California San Diego, San Diego, California, USA

${ }^{3}$ Department of Neurosurgery, University of California San Diego, San Diego, California, USA

${ }^{4}$ Department of Neurosciences and Pediatrics, University of California San Diego, San Diego, California, USA

\section{Correspondence to}

Dr John Ross Crawford, jrcrawford@ucsd.edu

\section{DESCRIPTION}

A 17-year-old girl with a clinical diagnosis of neurofibromatosis type 1 (NF-1) presented for a routine follow-up with worsening headaches, leftsided hemiparesis and hyper-reflexia. Her medical history was significant for prematurity, speech delay and mild left hemiparesis since the age of 10 years initially thought to be related to her prematurity. Physical examination revealed multiple café au lait macules and axillary freckling in addition to her hemiparesis. MRI brain showed a small right internal carotid and middle cerebral artery. Magnetic resonance angiogram demonstrated retrograde flow from the external carotid artery filling the middle and anterior cerebral arteries, consistent with Moyamoya disease. However, on sagittal and coronal MRI brain sequences an expanded cervical cord was appreciated and MRI spine revealed a non-contrast enhancing cervical cord tumour (figure 1). The patient underwent simultaneous encephalodurangiomyangiosis repair of the Moyamoya disease and subtotal resection of the cervical tumour without complication (figure 2). Pathology was consistent with a diagnosis of juvenile pilocytic astrocytoma. Moyamoya disease and low-grade spinal cord astrocytomas are known associations of NF-1. Moyamoya disease can be a presenting sign of weakness in patients with NF-1 and often show improvement following revascularisation procedures. ${ }^{1}$ Similarly, spinal cord low-grade gliomas associated with NF-1 can be asymptomatic. ${ }^{2}$ This case is unique in the simultaneous presentation and repair of comorbid conditions of NF-1 associated with weakness.
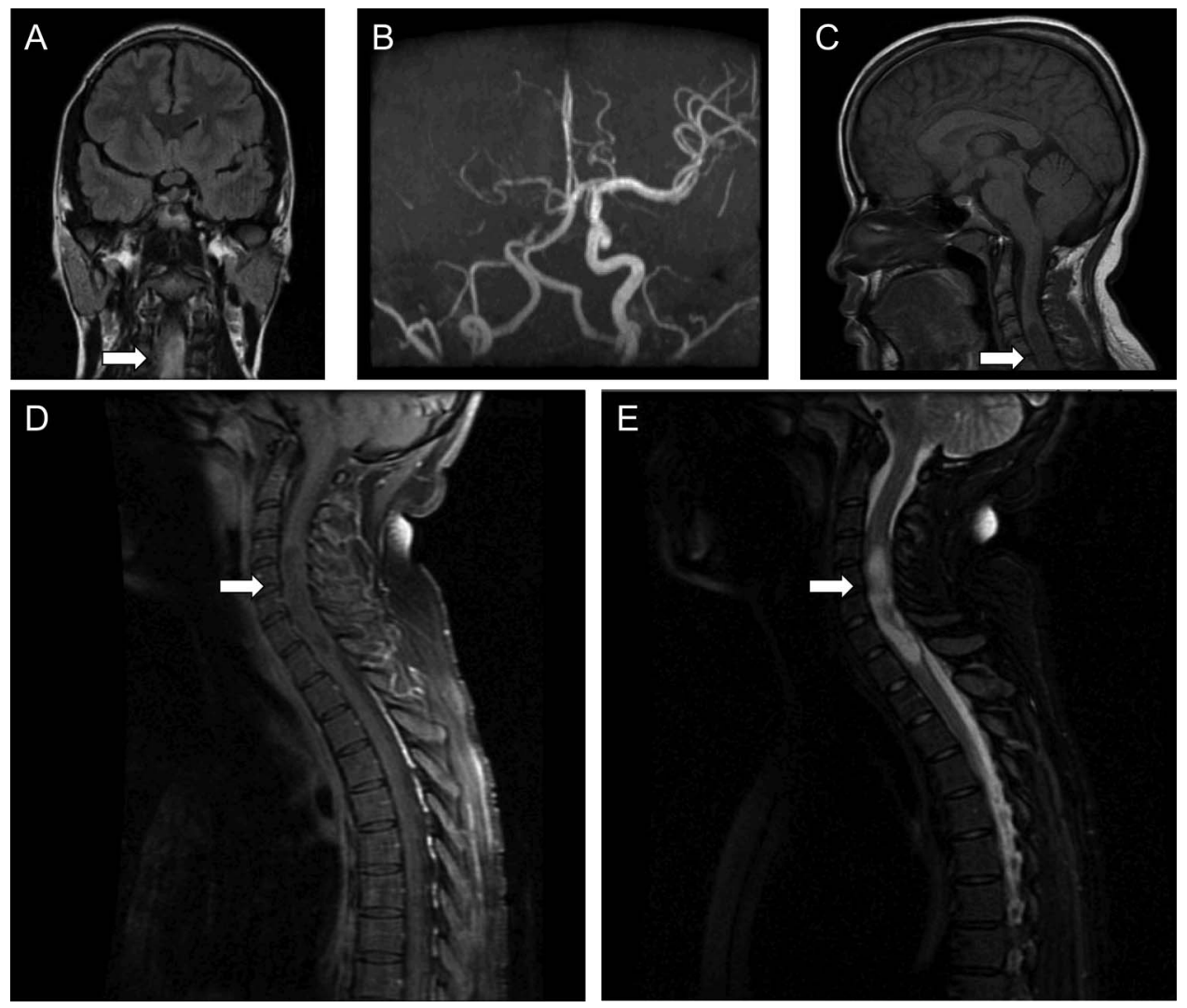

Figure 1 (A) Coronal fluid attenuated inversion recovery MRI brain demonstrates prominent $\mathrm{R}$ sylvian fissure consistent with atrophy, a stable optic glioma and cervical hyperintensity (arrow). (B) Magnetic resonance angiogram reveals narrowing of the right internal carotid and middle cerebral arteries consistent with Moyamoya disease. (C-E) MRI cervical spine demonstrates a non-contrast enhancing intramedullary juvenile pilocytic astrocytoma (arrow). 

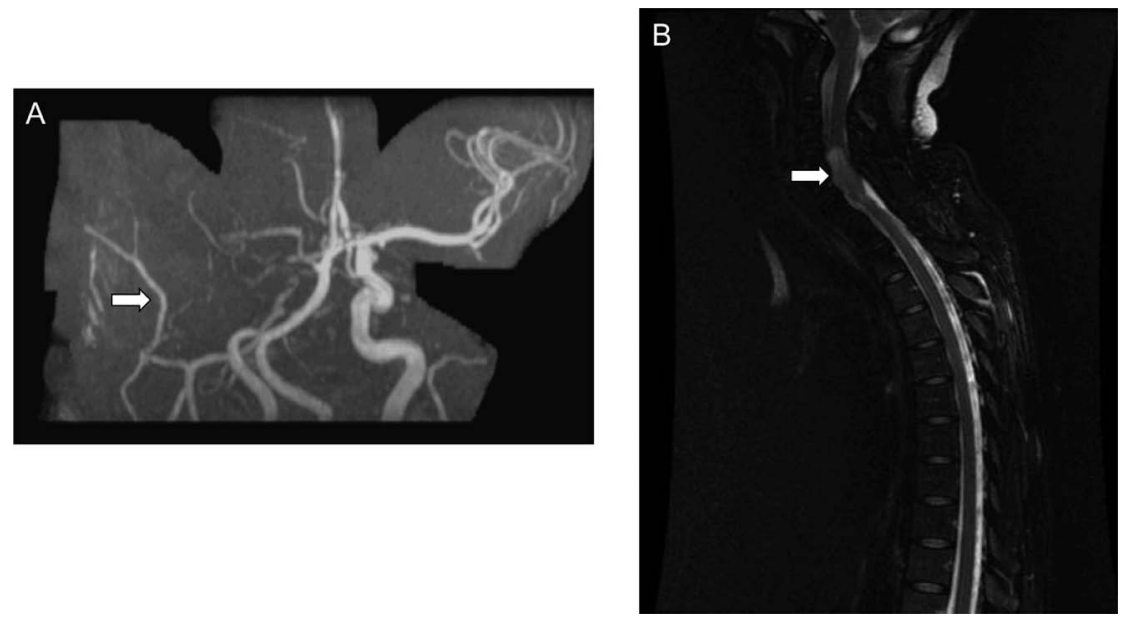

Figure 2 (A) Magnetic resonance angiogram of 6 months post encephalodurangiomyangiosis repair reveals evidence of early revascularisation (arrow). (B) Sagittal T2 MRI spine postoperatively reveals subtotal resection of intramedullary juvenile pilocytic astrocytoma.

\section{Learning points}

- Moyamoya disease can be a complication of neurofibromatosis type 1 (NF-1); identification is important because patients are likely to improve with revascularisation therapy.

- Spinal cord tumours are common in NF-1; patients with NF-1 and symptoms of weakness should undergo spinal imaging.

\section{Competing interests None.}

\section{Patient consent Obtained.}

Provenance and peer review Not commissioned; externally peer reviewed.

\section{REFERENCES}

1 Koss M, Scott RM, Irons MB, et al. Moyamoya syndrome associated with neurofibromatosis type 1: perioperative and long-term outcome after surgical revascularization. J Neurosurg Pediatr 2013;4:417-25.

2 Thakkar SD, Feigen U, Mautner VF. Spinal tumors in neurofibromatosis type 1: an MRI study of frequency, multiplicity and variety. Neuroradiology 1999;41:625-9.

Copyright 2013 BMJ Publishing Group. All rights reserved. For permission to reuse any of this content visit http://group.bmj.com/group/rights-licensing/permissions.

BMJ Case Report Fellows may re-use this article for personal use and teaching without any further permission.

Become a Fellow of BMJ Case Reports today and you can:

- Submit as many cases as you like

- Enjoy fast sympathetic peer review and rapid publication of accepted articles

- Access all the published articles

- Re-use any of the published material for personal use and teaching without further permission

For information on Institutional Fellowships contact consortiasales@bmjgroup.com

Visit casereports.bmj.com for more articles like this and to become a Fellow 